\title{
Transfusion practice in neonates
}

Do-Hyun Kim, MD, PhD

Department of Pediatrics, Dongguk University Ilsan Hospital, Goyang, Korea

Neonates, especially extremely low birth weight infants, are among the groups of patients undergoing transfusion frequently. Since they are exposed to higher specific transfusion risks compared to the patients of other age groups, there are many special aspects that must be considered for transfusion therapy in neonates. The transfusion risks in neonates include adverse outcomes specific for preterm infants as well as increased metabolic, immunologic, and infectious complications. To reduce the risks of transfusion-transmitted cytomegalovirus infection and transfusion-associated graft-versus-host disease, leukoreduced and irradiated cellular blood products should be used for all neonates. This review summarizes the risks of neonatal transfusion therapy, specific methods to reduce risk, and current trends and practices of red blood cell and platelet transfusions in neonates, to facilitate decision-making for neonatal transfusion.

Key words: Neonates, Transfusion, Red blood cell, Platelet

\section{Introduction}

Neonates are among the patients undergoing transfusion most frequently during hospitalization. More than 90\% of extremely low birth weight (ELBW) infants weighing less than $1,000 \mathrm{~g}$ are estimated to receive at least 1 red blood cell (RBC) transfusion during a neonatal intensive care unit (NICU) stay. ${ }^{1)}$ In addition, 60\% of very low birth weight (VLBW) infants will receive RBC transfusions during a NICU stay.

Neonatal transfusion practices are substantially different from adult and pediatric transfusion practices due to the unique physiological characteristics of neonates. First, the prenatal transfer of maternal antibodies to the immunologically immature neonate results in unique hematologic compatibility patterns different from those of other age groups. Second, immature organ function exposes the neonates to metabolic complications and to infectious and immunologic complications, such as transfusion-transmitted cytomegalovirus (TT-CMV) infection and transfusion-associated graft-versus-host disease (TA-GVHD). Third, neonates are at a higher risk of hemodynamic instability because of a small blood volume and the limited capacity to increase the blood volume relative to rapid growth. ${ }^{2)}$ These problems should be considered while performing transfusion therapy in neonates. This review focuses on the specific risks of transfusion therapy and the most recent evidence-based transfusion practices in neonates.

\section{Risks of transfusion therapy in neonates}

\section{Metabolic complications}

Hypoglycemia, hyperkalemia, and hypocalcemia are the most common metabolic complications associated with transfusion in neonates. Hypoglycemia can often result from

Corresponding author: Do-Hyun Kim, MD, PhD Department of Pediatrics, Dongguk University Ilsan Hospital, 27, Dongguk-ro, Ilsandong-gu, Goyang 10326, Korea

Tel: +82-31-961-7184

Fax: +82-31-961-7182

E-mail: dayeong1@hanmail.net https://orcid.org/0000-0002-5003-8475

Received: 6 August, 2018

Revised: 6 August, 2018

Accepted: 6 September, 2018
Copyright (C) 2018 by The Korean Pediatric Society

This is an open-access article distributed under the terms of the Creative Commons Attribution NonCommercial License (http://creativecommons.org/ licenses/by-nc/4.0/) which permits unrestricted noncommercial use, distribution, and reproduction in any medium, provided the original work is properly cited. 
decreased glucose infusion rates during transfusion in combination with impaired glycogenolysis and gluconeogenesis in preterm infants. In a study of 16 preterm infants, 15\% of those receiving RBCs preserved with Adsol (AS-1; adenine, glucose, mannitol, and sodium chloride) and 64\% of those receiving RBCs preserved with citrate-phosphate-dextrose-adenine required supplemental dextrose during the transfusion due to hypoglycemia. ${ }^{3)}$ The risk of hyperkalemia is entirely associated with the amount of $\mathrm{K}^{+}$load delivered with RBC transfusion. Irradiation may damage the RBC membranes, also causing hyperkalemia. In addition, transfusion of citrate-enriched blood products can cause hypocalcemia from citrate toxicity due to the immaturity of neonatal hepatic and renal function. Hyperkalemia and hypocalcemia are particularly of concern in neonates receiving exchange or massive ( $>20 \mathrm{~mL} / \mathrm{kg}$ of RBCs) transfusions.

\section{Immunologic complications}

In neonates, immunologic complications include hemolytic transfusion reactions, allergic reactions, febrile nonhemolytic reactions, immune-mediated platelet destruction, transfusion related acute lung injury (TRALI), T-antigen activation, and TA-GVHD. Currently, TRALI is the most common cause of acute transfusion fatality among all blood recipients, accounting for 37\% of the deaths. However, it is uncertain whether TRALI occurs in neonates. ${ }^{4}$ TA-GVHD occurs in immunosuppressed or immunodeficient recipients whose immune system is unable to recognize transfused immunocompetent T lymphocytes. TA-GVHD may be present in neonates for a longer duration before the onset of clinical manifestations and death compared to that in adults. In a literature review of neonatal TA-GVHD, the median durations of clinical manifestations were 28 (fever), 30 (rash), 43 (leukopenia), and 51 (death, all neonates) days. ${ }^{5)}$ Neonates, especially preterm infants, are at risk for TA-GVHD. Neonates at high risk for TA-GVHD include extremely premature neonates, those receiving intrauterine or exchange transfusions, and those receiving cellular blood products from a blood relative. ${ }^{2)}$ Pretransfusion gamma irradiation of cellular blood products can inactivate donor T lymphocytes and consequently reduce the risk of TA-GVHD. ${ }^{6}$

\section{Infectious complications}

Many infectious agents such as viruses, bacteria, protozoa, and other pathogens, can be transmitted by blood transfusion. Among these pathogens, the prevalence of human CMV is reported to be $30 \%$ to $70 \%$ in blood donors within the United States. Human CMV can be latent within the leukocytes of immunocompetent donors and transmitted by transfusion of cellular blood products into seronegative recipients. In particular, premature, seronegative neonates weighing less than $1,250 \mathrm{~g}$ at birth and fetuses receiving intrauterine transfusions are at high risk for TT-CMV-associated morbidity and mortality. ${ }^{2,7)}$ Transfusion of CMV-seronegative blood is considered necessary to preventing TT-CMV infections, but such products are difficult to obtain due to the high prevalence of CMV seropositivity. Since CMV remains latent within the leukocytes, leukocyte reduction is also effective in preventing TT-CMV infections in neonates. Currently, the use of leukoreduction filters in the collection of cellular blood products is strongly recommended for recipients at high risk for TT-CMV infection. ${ }^{2)}$ A prospective study with 539 VLBW infants reported that the incidence of TTCMV infection was 0.0\% (95\% confidence interval [CI], 0-0.3) when using CMV-seronegative and leukoreduced blood products. ${ }^{8)}$ Nevertheless, transfusion of leukoreduced blood from CMV-untested donors was also relatively safe and had a low risk of TT-CMV infection. ${ }^{9,10)}$ The important thing is that transfusion with CMVuntested leukoreduced blood should not be delayed because CMVseronegative blood is unavailable. ${ }^{11)}$

\section{Transfusion-related adverse outcomes}

Recently, several studies have suggested the association between RBC transfusion and adverse outcomes specific to preterm infants. First, an association between RBC transfusion and the development of bronchopulmonary dysplasia (BPD) has been reported. ${ }^{12-14)}$ Iron and free radical injury were presumed as possible mechanisms underlying the development of BPD. ${ }^{15)}$ Second, some researchers reported that the development of necrotizing enterocolitis (NEC) was closely associated with RBC transfusion. ${ }^{16-18)}$ Using nearinfrared spectroscopy, Marin et al. ${ }^{19)}$ demonstrated that fluctuation of mesenteric blood flow was more pronounced in VLBW infants who developed transfusion-related NEC, compared to transfused infants who did not develop NEC. In addition, a policy of withholding feeding during transfusion was suggested to be a protective intervention against the development of NEC. ${ }^{20)}$ Immunologic or ischemia/reperfusion injury to the intestine was suggested as a presumed mechanism for transfusion-related $\mathrm{NEC}^{2)}$ Third, a previous report described an association between early RBC transfusion and subsequent development of severe intraventricular hemorrhage (IVH) in VLBW infants. ${ }^{21)}$ A study showed that an association exists between RBC transfusion and extension of a grade 1 IVH into a grade 3 or $4 \mathrm{IVH}^{22)}$ In a retrospective study during a 9-year period, Christensen et al. ${ }^{23)}$ found that a more restrictive transfusion strategy during the first week after birth was associated with a decreased rate of severe IVH in VLBW infants. Some studies have also suggested an association between RBC transfusion and the development of retinopathy of prematurity (ROP). The association was dependent on the dose or the frequency of RBC transfusion. ${ }^{24,25)}$ Although many studies have reported correlations between blood transfusions and the development of adverse outcomes in preterm infants, the causal relationship is still not clear and little is known of the underlying pathophysiology of this relationship. 


\section{Specific methods to decrease the risks of transfu- sion therapy in neonates}

\section{Leukocyte reduction}

Leukoreduced blood cells should be used in all neonates. Currently, leukoreduction filters can remove approximately 99.9\% of white blood cells from blood cells. ${ }^{26)}$ Universal leukoreduction significantly decreases the rates of febrile nonhemolytic transfusion reactions, alloimmunization, allergic reactions, and the transmission of certain infections (especially CMV infection). ${ }^{27)}$ Interestingly, use of universal leukoreduction was associated with a decreased incidence of BPD (odds ratio [OR], 0.42; 95\% CI, 0.25-0.70), ROP (OR, 0.56; 95\% CI, 0.33-0.93), and NEC (OR, 0.39; 95\% CI, 0.17$0.90)$ in preterm infants requiring $\mathrm{RBC}$ transfusions. ${ }^{28)}$ However, the primary objective of leukoreduction in neonates is to reduce TT-CMV infection. Since leukoreduction cannot remove all lymphocytes, TA-GVHD cannot be prevented by leukoreduction. The current Korean Transfusion Guideline specifies universal leukoreduction before transfusing packed RBC or platelet concentrates in neonates. ${ }^{29)}$

\section{Irradiation of cellular blood products}

As mentioned previously, irradiation of cellular blood products reduces the incidence of TA-GVHD in susceptible recipients. Irradiation increases potassium leakage from stored RBCs and reduces the shelf life of irradiated RBCs. The recommended shelf life of irradiated RBCs is 28 days compared with 42 days for nonirradiated RBCs. Irradiation of blood products does not also prevent TTCMV infection. ${ }^{27)}$ The indications for irradiation of blood products in neonates by Fasano et al. ${ }^{2)}$ are as follows: (1) transfusion to premature infants with birth weight $<1,200 \mathrm{~g}$, (2) intrauterine transfusion, (3) transfusion of a cellular blood component obtained from a blood relative, and (4) transfusion of an HLA-matched or plateletcross-matched product. In a survey of transfusion policies in the United States and Canada, the majority of institutions routinely irradiate cellular blood products for all neonates, or at least for preterm infants. ${ }^{30)}$ According to the Korean Transfusion Guideline, ${ }^{29)}$ the indications for irradiation include transfusion to all fetuses, premature infants, and low birth weight infants in addition to neonatal exchange transfusion.

\section{Current trends and practices of RBC transfusion in neonates}

\section{Indications}

The debate on whether to adopt liberal (high hemoglobin threshold) versus restrictive (low hemoglobin threshold) transfusion strategies in neonates remains unsolved. Two important clinical trials have compared the risks and benefits of RBC transfusion
Table 1. Red blood cell transfusion thresholds for preterm infants in 2 randomized trials

\begin{tabular}{lcc}
\hline Strategy & |owa Tria $^{31)}$ & PINT Tria $^{32)}$ \\
\hline Liberal strategy & & \\
Upper & 15.3 & 13.5 \\
Lower & 10.0 & 8.5 \\
Restrictive strategy & & \\
Upper & 11.3 & 11.5 \\
Lower & 7.3 & 7.5 \\
\hline
\end{tabular}

Thresholds are hemoglobin levels $(\mathrm{g} / \mathrm{dL})$

PINT, premature infants in need of transfusion.

using both transfusion strategies. ${ }^{31,32)}$ Table 1 shows upper and lower thresholds of RBC transfusion for preterm infants in 2 trials. The Iowa trial by Bell et al. ${ }^{31)}$ reported that there was no difference between the liberal and restrictive groups in avoiding transfusion, but the restrictive group showed more frequent adverse neurological events such as intraparenchymal brain hemorrhage and periventricular leukomalacia, and more episodes of apnea. In addition, the PINT (premature infants in need of transfusion) trial by Kirpalani et al. ${ }^{32}$ suggested that infants in the restrictive group were more likely to avoid transfusion, but that there were no significant differences between both groups regarding morbidity, such as survival rates, BPD, brain injury, and ROP. Taken together, a metaanalysis in 2011 including a long-term study by Whyte et al. ${ }^{33)}$ showed the following findings: (1) the restrictive group received fewer transfusions and lowered donor exposures than the liberal group, (2) there were no differences between both groups in the rate of mortality and serious morbidity at discharge, and (3) there were no differences between both groups at 18 to 21 months of corrected age in mortality, major morbidity, and serious neurodevelopmental impairment. ${ }^{34)}$ Based on these findings, use of the restrictive strategy is preferred to decrease exposure to transfusions. ${ }^{35}$ Transfusion should be carefully determined by comparing the anticipated effects and risks according to the clinical condition as well as the hematocrit level. The current indications for RBC transfusion according to the "Manual of Neonatal Care" published in the Korean Society of Neonatology are listed in Table 2. ${ }^{36)}$

\section{Dose and administration}

Generally, neonates receive RBC transfusions at a dose of 10 to $15 \mathrm{~mL} / \mathrm{kg}$ (a maximum of $20 \mathrm{~mL} / \mathrm{kg}$ ) for 1 to 2 hours and the transfusion should be completed within 4 hours. It is estimated that the hemoglobin level of the newborn increases by about 2 to $3 \mathrm{~g} /$ $\mathrm{dL}$ at this dose ${ }^{37)}$ In a multicenter randomized trial for determining whether transfusion of fresh RBCs stored for 7 days or less improved the outcomes in VLBW infants compared with standard-issue RBCs, there were no differences in mortality and major morbidities such as NEC, severe IVH, severe ROP, and BPD between 2 groups. This finding suggests that alteration in the standard RBCs storage time is 
Table 2. Indications for red blood cell transfusion in neonates

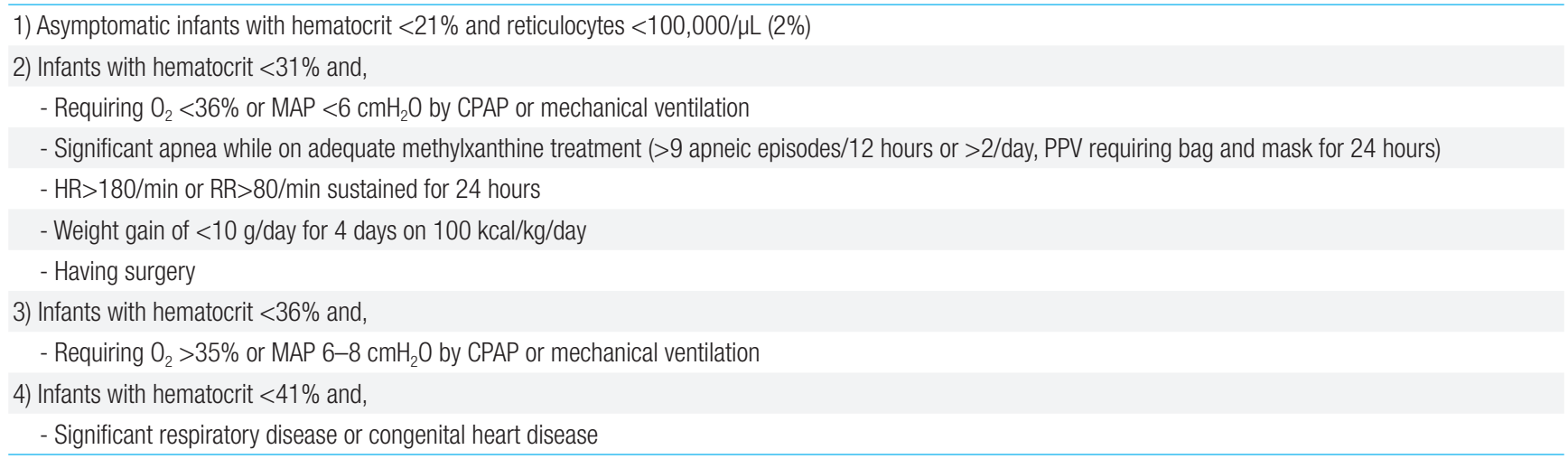

Modified from Korean Society of Neonatology, Manual of neonatal care. 3rd ed. 2014:303. ${ }^{36}$

MAP, mean airway pressure; CPAP, continuous positive airway pressure; PPV, positive pressure ventilation; HR, heart rate; RR, respiratory rate.

not required for preterm infants. ${ }^{38)}$

\section{Small-volume transfusion}

Since neonates, especially ELBW infants are so small, small volume (10 to $15 \mathrm{~mL} / \mathrm{kg}$ ) transfusion requires the use of special equipment such as small bags (satellite packs) and sterile connecting devices. Using a sterile connecting device, the blood from a large blood unit ( 320 to $400 \mathrm{~mL}$ ) can be transferred into several small bags in a sterile manner through a closed system. It has been found that such a system is safe and can prevent blood waste. In addition, it can reduce the donor exposure by increasing the number of transfusions from a single blood unit. ${ }^{2,27)}$

\section{Current trends and practices of platelet transfusion in neonates}

There are diverse guidelines for neonatal platelet transfusion across institutions and countries, mainly based on the clinical experience and expert opinion. Due to the concern regarding IVH in high-risk newborns, many clinicians have traditionally tended to significantly mitigate the indication for platelet transfusion. In a study of 53 neonates with severe thrombocytopenia, a platelet count threshold of $30,000 / \mu \mathrm{L}$ without previous IVH or other risk factors or $50,000 / \mu \mathrm{L}$ with previous IVH or clinical instability was safe in the majority of neonates. ${ }^{39)}$ In addition, a prospective observational study of 169 neonates showed that a more restrictive strategy for platelet transfusion using platelet count thresholds of $25,000 / \mu \mathrm{L}$ in stable neonates and 50,000/ $\mathrm{LL}$ in unstable neonates did not increase the risk of IVH. ${ }^{40)}$ In a retrospective cohort study of VLBW infants, the following 2 strategies were compared: (1) liberal transfusion for a platelet count less than 50,000/ $\mu \mathrm{L}$ in stable neonates or $100,000 / \mu \mathrm{L}$ in unstable neonates, (2) restrictive transfusion for a platelet count less than $25,000 / \mu \mathrm{L}$ in stable neonates or $50,000 / \mu \mathrm{L}$ in unstable
Table 3. Indications for platelet transfusion in neonates

1) Platelet count $<30,000 / \mu \mathrm{L}$ : transfuse all

2) Platelet count $30,000-49,000 / \mu \mathrm{L}$ and,

- Body weight $<1,500 \mathrm{~g}$ and $\leq 7$ days old

- Clinically unstable

- Concurrent coagulopathy

- Previous significant hemorrhage (i.e., IVH grade 3 or 4)

- Prior to surgical procedure

- Postoperative period ( $<72$ hours)

3) Platelet count $50,000-100,000 / \mu \mathrm{L}$ and,

- Acute bleeding

- NAIT with intracranial bleeding

- Before or after neurosurgical procedure

Modified from Korean Society of Neonatology, Manual of neonatal care. 3rd ed. 2014:315. ${ }^{42)}$

IVH, intracranial hemorrhage; NAIT, neonatal alloimmune thrombocytopenia.

neonates. In this study, the restrictive strategy for platelet transfusion was not associated with increased rates of IVH and mortality. ${ }^{41)}$ The indications for platelet transfusion according to the "Manual of Neonatal Care" published in the Korean Society of Neonatology are listed in Table $3{ }^{42)}$ Usually, an increase of 50,000 to $100,000 / \mu \mathrm{L}$ in the platelet count can be expected through platelet transfusions of 10 to $15 \mathrm{~mL} / \mathrm{kg}$ within 2 hours in neonates.

\section{Conclusion}

When transfusing neonates, particularly preterm infants, efforts should be made to reduce donor exposure, TT-CMV infection, and TA-GVHD. Such efforts include: (1) reduce the number of blood transfusions as much as possible, (2) use special equipment such as small bags (satellite packs) and sterile connecting devices for small-volume transfusion, and (3) use leukoreduced and irradiated cellular blood products. Moreover, transfusion of RBCs or platelet 
in neonates should be carefully determined by comparing the anticipated effects and risks according to the clinical condition, as well as the hematocrit or platelet levels.

\section{Conflicts of interest}

No potential conflict of interest relevant to this article was reported.

\section{References}

1. Maier RF, Sonntag J, Walka MM, Liu G, Metze BC, Obladen M. Changing practices of red blood cell transfusions in infants with birth weights less than $1000 \mathrm{~g}$. J Pediatr 2000;136:220-4.

2. Fasano RM, Said M, Luban NL. Blood component therapy for the neonate. In: Martin RJ, Fanaroff AV, Walsh MC, editors. Fanaroff and Martin's neonatal-perinatal medicine: diseases of the fetus and infant. 10th ed. Philadelphia (PA): Elsevier Saunders, 2015:1344-61.

3. Goodstein MH, Locke RG, Wlodarczyk D, Goldsmith LS, Rubenstein SD, Herman JH. Comparison of two preservation solutions for erythrocyte transfusions in newborn infants. J Pediatr 1993;123:7838.

4. U.S. Food and Drug Administration. Fatalities reported to FDA following blood collection and transfusion: annual summary for fiscal year 2012 [Internet]. Silver Spring (MD): U.S. Food and Drug Administration; [cited 2018 May 15]. Available from: http://www.fda.gov/ BiologicsBloodVaccines/SafetyAvailability/ReportaProblem/ TransfusionDonationFatalities/ucm346639.htm.

5. Ohto H, Anderson KC. Posttransfusion graft-versus-host disease in Japanese newborns. Transfusion 1996;36:117-23.

6. Linden JV, Pisciotto PT. Transfusion-associated graft-versus-host disease and blood irradiation. Transfus Med Rev 1992;6:116-23.

7. Fasano R, Luban NL. Blood component therapy. Pediatr Clin North Am 2008;55:421-45, ix.

8. Josephson CD, Caliendo AM, Easley KA, Knezevic A, Shenvi N, Hinkes MT, et al. Blood transfusion and breast milk transmission of cytomegalovirus in very low-birth-weight infants: a prospective cohort study. JAMA Pediatr 2014;168:1054-62.

9. Delaney M, Mayock D, Knezevic A, Norby-Slycord C, Kleine E, Patel $\mathrm{R}$, et al. Postnatal cytomegalovirus infection: a pilot comparative effectiveness study of transfusion safety using leukoreduced-only transfusion strategy. Transfusion 2016;56:1945-50.

10. Strauss RG. Optimal prevention of transfusion-transmitted cytomegalovirus (TTCMV) infection by modern leukocyte reduction alone: CMV sero/antibody-negative donors needed only for leukocyte products. Transfusion 2016;56:1921-4.

11. Patel RM, Josephson CD. Neonatal transfusion. In: Gleason CA, Juul SE, editors. Avery's of the newborn. 10th ed. Philadelphia (PA): Elsevier Saunders, 2018:1180-6.

12. Cooke RW, Drury JA, Yoxall CW, James C. Blood transfusion and chronic lung disease in preterm infants. Eur J Pediatr 1997;156:4750.

13. Valieva OA, Strandjord TP, Mayock DE, Juul SE. Effects of transfusions in extremely low birth weight infants: a retrospective study. J Pediatr 2009;155:331-37.e1.

14. Zhang Z, Huang X, Lu H. Association between red blood cell transfusion and bronchopulmonary dysplasia in preterm infants. Sci Rep
2014;4:4340.

15. Korhonen P, Tammela O, Koivisto AM, Laippala P, Ikonen S. Frequency and risk factors in bronchopulmonary dysplasia in a cohort of very low birth weight infants. Early Hum Dev 1999;54:245-58.

16. Mally P, Golombek SG, Mishra R, Nigam S, Mohandas K, Depalhma H, et al. Association of necrotizing enterocolitis with elective packed red blood cell transfusions in stable, growing, premature neonates. Am J Perinatol 2006;23:451-8.

17. Josephson CD, Wesolowski A, Bao G, Sola-Visner MC, Dudell G, Castillejo MI, et al. Do red cell transfusions increase the risk of necrotizing enterocolitis in premature infants? J Pediatr 2010;157: 972-8.e1-3.

18. Blau J, Calo JM, Dozor D, Sutton M, Alpan G, La Gamma EF. Transfusion-related acute gut injury: necrotizing enterocolitis in very low birth weight neonates after packed red blood cell transfusion. J Pediatr 2011;158:403-9.

19. Marin T, Moore J, Kosmetatos N, Roback JD, Weiss P, Higgins M, et al. Red blood cell transfusion-related necrotizing enterocolitis in verylow-birthweight infants: a near-infrared spectroscopy investigation. Transfusion 2013;53:2650-8.

20. El-Dib M, Narang S, Lee E, Massaro AN, Aly H. Red blood cell transfusion, feeding and necrotizing enterocolitis in preterm infants. $\mathrm{J}$ Perinatol 2011;31:183-7.

21. Christensen RD. Associations between "early" red blood cell transfusion and severe intraventricular hemorrhage, and between "late" red blood cell transfusion and necrotizing enterocolitis. Semin Perinatol 2012;36:283-9.

22. Baer VL, Lambert DK, Henry E, Snow GL, Christensen RD. Red blood cell transfusion of preterm neonates with a Grade 1 intraventricular hemorrhage is associated with extension to a Grade 3 or 4 hemorrhage. Transfusion 2011;51:1933-9.

23. Christensen RD, Baer VL, Lambert DK, Ilstrup SJ, Eggert LD, Henry E. Association, among very-low-birthweight neonates, between red blood cell transfusions in the week after birth and severe intraventricular hemorrhage. Transfusion 2014;54:104-8.

24. Inder TE, Clemett RS, Austin NC, Graham P, Darlow BA. High iron status in very low birth weight infants is associated with an increased risk of retinopathy of prematurity. J Pediatr 1997;131:541-4.

25. Dani C, Reali MF, Bertini G, Martelli E, Pezzati M, Rubaltelli FF. The role of blood transfusions and iron intake on retinopathy of prematurity. Early Hum Dev 2001;62:57-63.

26. Galal SA. Therapeutic techniques. Selection of blood components for neonatal transfusion. NeoReviews 2005;6:c351-5.

27. Dos Santos AM, Trindade CE. Red blood cell transfusions on the neonate. NeoReviews 2011;12:c13-9.

28. Fergusson D, Hébert PC, Lee SK, Walker CR, Barrington KJ, Joseph L, et al. Clinical outcomes following institution of universal leukoreduction of blood transfusions for premature infants. JAMA 2003;289: 1950-6.

29. Korea Centers for Disease Control and Prevention. Korean society of blood transfusion. Transfusion Guideline. 4th ed. Cheongju (Korea): Korea Centers for Disease Control and Prevention, 2016.

30. Spinella PC, Dressler A, Tucci M, Carroll CL, Rosen RS, Hume H, et al. Survey of transfusion policies at US and Canadian children's hospitals in 2008 and 2009. Transfusion 2010;50:2328-35.

31. Bell EF, Strauss RG, Widness JA, Mahoney LT, Mock DM, Seward VJ, et al. Randomized trial of liberal versus restrictive guidelines for red blood cell transfusion in preterm infants. Pediatrics 2005;115:168591.

32. Kirpalani H, Whyte RK, Andersen C, Asztalos EV, Heddle N, Blajchman MA, et al. The Premature Infants in Need of Transfusion (PINT) study: a randomized, controlled trial of a restrictive (low) 
versus liberal (high) transfusion threshold for extremely low birth weight infants. J Pediatr 2006;149:301-7.

33. Whyte RK, Kirpalani H, Asztalos EV, Andersen C, Blajchman M, Heddle N, et al. Neurodevelopmental outcome of extremely low birth weight infants randomly assigned to restrictive or liberal hemoglobin thresholds for blood transfusion. Pediatrics 2009;123:207-13.

34. Whyte R, Kirpalani H. Low versus high haemoglobin concentration threshold for blood transfusion for preventing morbidity and mortality in very low birth weight infants. Cochrane Database Syst Rev 2011;(11):CD000512.

35. Ekhaguere OA, Morriss FH Jr, Bell EF, Prakash N, Widness JA. Predictive factors and practice trends in red blood cell transfusions for very-low-birth-weight infants. Pediatr Res 2016;79:736-41.

36. Korean Society of Neonatology. Manual of neonatal care. 3rd ed. Seoul (Korea): Korean Society of Neonatology, 2014:303.

37. Hensch LA, Indrikovs AJ, Shattuck KE. Transfusion in extremely lowbirth-weight premature neonates: current practices trends, risks, and early interventions to decrease the need for transfusion. NeoReviews 2015;16:c287-96.

38. Fergusson DA, Hébert P, Hogan DL, LeBel L, Rouvinez-Bouali N, Smyth JA, et al. Effect of fresh red blood cell transfusions on clinical outcomes in premature, very low-birth-weight infants: the ARIPI randomized trial. JAMA 2012;308:1443-51.

39. Murray NA, Howarth LJ, McCloy MP, Letsky EA, Roberts IA. Platelet transfusion in the management of severe thrombocytopenia in neonatal intensive care unit patients. Transfus Med 2002;12:35-41.

40. Muthukumar P, Venkatesh V, Curley A, Kahan BC, Choo L, Ballard S, et al. Severe thrombocytopenia and patterns of bleeding in neonates: results from a prospective observational study and implications for use of platelet transfusions. Transfus Med 2012;22:338-43.

41. Borges JP, dos Santos AM, da Cunha DH, Mimica AF, Guinsburg R, Kopelman BI. Restrictive guideline reduces platelet count thresholds for transfusions in very low birth weight preterm infants. Vox Sang 2013;104:207-13.

42. Korean Society of Neonatology. Manual of neonatal care. 3rd ed. Seoul (Korea): Korean Society of Neonatology, 2014:315. 